\title{
Perancangan Sistem Informasi Pemesanan Undangan Dan Yasin Pada CV. Kurnia Berbasis Web
}

\author{
Andika1, Eva Zuraidah ${ }^{2}$ \\ ${ }^{1}$ Teknologi Informasi/Universitas Bina Sarana Informatika. \\ ${ }^{2}$ Sistem Informasi / STMIK Nusa Mandiri \\ e-mail: ${ }^{1}$ andika.03121996@gmail.com \\ 2eva.evz@nusamandiri.ac.id

\begin{tabular}{ccc}
\hline Diterima & Direvisi & Disetujui \\
$02-02-2020$ & $08-05-2020$ & $20-05-2020$ \\
\hline
\end{tabular}

\begin{abstract}
Abstrak- CV. Kurnia proses pemesanan masih dilakukan secara manual yaitu masih menggunakan kertas yang rangkap 2, menjadi suatu keborosan pada kertas dan juga kertas itu sering hilang, kena basah. Adapun tujuan dari penelitian ini adalah untuk merancang sistem informasi pemesanan pada CV. Kurnia untuk memudahkan consumen memesan undangan dan buku Yasin, serta motif dari Undangan yang diinginkan, begitu juga untuk cara pembayaran tidak perlu lagi untuk datang membawa uang ke CV kurnia, pengirimannya juga akan diantar ketempat pemesan. Adapun metode-metode yang digunakan untuk penelitian ini adalah metode pendekatan menggunakan sistem berorientasi objek sementara metode pengembangan sistem yang digunakan adalah Waterfall model. Sistem model mengunakan metode Unifield Modeling Languange (UML) dengan mengunakan bahasa pemograman Hypertext Preprocessor (PHP) sedangkan Sofware atau Tools yang digunakan adalah MySQL sebagai basis datanya. Oleh karena itu penulis web untuk percetakan yang sudah memiliki pelanggan, agar dapat memenuhi keinginan pelanggan yang menuntut adanya kemudahan dalam memesan barang yang diinginkan.dengan adanya web ini percetakan juga dapat bersaing dengan percetakan lainnya, karena dapat meningkatkan kualitasnya dalam memberikan kemudahan kepada pelanggannya. Didalam web percetakan ini terdapat informasi mengenai barang yang dapat dipesan, baik itu gambar, deskripsi barang, maupun harganya, dengan adanya berbasis web ini merupakan solusi untuk memecahkan permasalahan yang efektif dan efesien dalam pembuatan laporan pembelian dan laporan pemesanan, agar mengetahui histori data pesanan yang lebih akurat serta mengurangi kesalahan lainnya dalam proses transaksi. Diharapkan dengan adanya website ini dapat membuat masyarakat mengetahui dan tertarik untuk memesan undangan dan Yasin di web tersebut..
\end{abstract}

Kata Kunci PHP Perancangan Sistem Informasi, Sistem Pemesanan, Waterfall

Abstrack CV. The full order process is still done manually, that is still using double paper, it becomes a waste of paper and the paper is often lost, wet. The purpose of this research is to design an ordering information system on the CV. Kurnia is to facilitate consumers to order invitations and Yasin books, as well as the motives of the desired invitation, as well as for payment methods no longer need to come to bring money to CV Kurnia, the delivery will also be delivered to the place of the buyer. The methods used for this research are the method of the approach using object-oriented systems while the system development method used is the Waterfall model. The model system uses the Unified Modeling Language (UML) method by using the Hypertext Preprocessor (PHP) programming language while the Software or Tools used are MySQL as the database. Therefore, web writers for printing who already have customers, to meet the desires of customers who demand the ease of ordering the desired goods. With this web, printing can also compete with other printing because it can improve its quality in providing convenience to its customers. In this printing web there is information about items that can be ordered, be it pictures, descriptions of goods, and prices, with this web-based solution is to solve problems that are effective and efficient in making purchase reports and order reports, in order to know the order data history. more accurate and reduce other errors in the transaction process. It is hoped that this website can make people aware of and interested in ordering invitations and Yasin on the web

Keywords PHP Information System Design, Ordering System, Waterfall

\section{PENDAHULUAN}

Percetakan merupakan salah satu jenis usaha yang menarik untuk dijalankan dan memiliki berbagai maca barang yang terdapat di dalamnya. Percetakan merupakan usaha yang banyak diminati oleh masyarakat yang ingin memiliki usaha, baik 
dalam skala besar maupun skala kecil. Percetakan yang umum dan banyak dipesan ialah untuk mencetak kop surat, brosur, spanduk, banner, undangan, yasin dan sebagainya. Karena pencetakan hal-hal tersebut dilakukan secara terusmenerus, dan dalam suatu instansi harus selalu tersedia sebelum barang habis

CV. Kurnia merupakan salah satu perusahaan yang bergerak di bidang percetakan. CV. Kurnia mendapat permasalahan yang sering timbul akibat promosi atau informasi yang masih menggunakan brosur atau pamphlet. Hal tersebut membuat CV. Kurnia ini kesulitan dalam penyampaian informasi tentang produk yang dipasarkan pada pelanggan. Selain itu dalam hal pemesanan, seperti pemesanan undangan pernikahan, undangan khitanan dan yasin masih belum optimal dikarenakan pelanggan harus dating langsung ke tempat percetakan CV, Kurnia $\mathrm{Hal}$ ini tentunya sangat berpengaruh pada penjualan dan pemasaran di CV. Kurnia yang belum memiliki jaringan yang luas untuk pemasarannya.

CV. Kurnia proses pemesanan masih dilakukan secara manual yaitu masih menggunakan kertas yang rangkap 2, menjadi suatu keborosan pada kertas dan juga kertas itu sering hilang, kena basah. Adapun tujuan dari penelitian ini adalah untuk merancang sistem informasi pemesanan pada $\mathrm{CV}$. Kurnia untuk memudahkan consumen memesan undangan dan buku Yasin, serta motif dari Undangan yang diinginkan, begitu juga untuk cara pembayaran tidak perlu lagi untuk datang membawa uang ke CV kurnia, pengirimannya juga akan diantar ketempat pemesan

Perkembangan teknologi internet saat ini telah berkembang sangat pesat. Hal ini menyebabkan terjadinya perubahan yang tidak bisa kita hindari sehingga dituntut untuk bisa mengikuti perkembangan teknologi yang ada. Adanya internet dapat menunjang tujuan maksimal yang diharapkan, dapat menghemat biaya, tenaga dan waktu operasional perusahaan sebagai sarana komunikasi, publikasi, serta sarana untuk mendapatkan berbagai informasi secara luas (Salamah \& Khasanah, 2017)

Pada pembangunan sistem ini metode yang digunakan yaitu metode Waterfall. Model ini adalah model klasik yang bersifat sistematis, berurutan dalam membangun software ( Maryani dkk, 2018).

Teknologi internet yang di dalamnya terdapat basis arsitektur berupa aplikasi web dan komunikasi data. Dalam segi penggunaan, geografis maupun implementasinya, Intranet bekerja secara luas dan maksimal seperti halnya Internet. Namun demikian Intranet sangat terbatas dalam hal privilege dan hak akses para pemakainya. (Maryani dkk, 2018)

Web server adalah suatu program kompter yang mempunyai tanggung jawab atau tugas menerima perintah HTTP dari komputer klien, yang dikenal dengan nama web browser, dan melayani mereka dengan menyediakan respon HTTP berdau konten data, biasanya berup halaman web yang terdiri dari dokumen HTML, dan objek terkait seperti gambar dan lain-lain. (Andi 2015:269)

Web Browser adalah aplikasi perangkat lunak yang memungkinkan penggunanya untuk berinteraksi dengan teks, image, video, games, dan informasi lainnya yang berlokasi pada halaman web pada World Wide Web (WWW) atau Local Area Network (LAN). (Maryani dkk, 2018)).

MySQL merupakan software yang bersifat Open Source, yang berarti software di lengkapi dengan kode yang digunakan untuk membuat MySQL, selain kode yang bisa dijalankan secara langsung pada sistem operasi, dan bisa diperoleh dengan cara men-download (mengunduh) di internet secara gratis. MySQL juga tergolong sebagai DBMS (Database Management System). (Salamah 2018)

PHP (Hypertext Preprocessor) adalah sebuah bahasa pemrograman scripting untuk membuat halaman yang dinamis. Maksud dari scripting adalah pembuatannya menggunakan editor teks biasa, seperti Notepad, Notepad++, dan lainnya. Meskipun dikenal sebagai bahasa dalam membuat halaman $w e b$, tetapi sebenarnya PHP juga bisa digunakan dalam pembuatan aplikasi command line dan juga GUI (Salamah U, Khasanah, 2017)

$X A M P P$ adalah sebuah software yang berfungsi untuk menjalankan website berbasis PHP dan menggunakan pengolah data MySQL di komputer lokal. (Maryani dkk, 2018) .

Apache merupakan aplikasi web server. Tugas utama dari Apache adalah menghasilkan halaman web yang benar kepada user berdasarkan kode PHP yang dituliskan oleh pembuat web atau user. ( Gea, S., \& Masalah, P, 2016)

Pada pembangunan sistem ini metode yang digunakan yaitu metode Waterfall. Model ini adalah model klasik yang bersifat sistematis, berurutan dalam membangun software.(Maryani, Ishaq, \& Mulyadi, 2018).

Entity Relationship Diagram (ERD) mendeskripsikan hubungan antar data dalam basis data berdasarkan objek-objek data yang memiliki hubungan antar relasi. (Salamah U, Khasanah, 2017).

Menurut Hasugian dan Shidiq dalam (Puspitasari Studi, dan Informatika, 2016): menyimpulkan bahwa: Sebuah model sistem yang digambarkan dengan sebuah diagram-ER akan mengikuti pola/ aturan pemodelan tertentu dalam kaitannya dengan konversi ke $L R S$, maka perubahan yang terjadi adalah mengikuti aturan - aturan berikut ini : Setiap entitas akan diubah kebentuk kotak, Sebuah atribut relasi disatukan dalam sebuah kotak bersama entitas yang terjadi pada diagram-ER 1:M (relasi bersatu dengan cardinality $\mathrm{M}$ ) atau tingkat hubungan 1:1 (relasi bersatu dengan cardinality yang paling membutuhkan referensi), sebuah relasi dipisah dalam sebuah kotak tersendiri (menjadi entitas baru) jika tingkat hubungannya M:M (many to many) dan memiliki foreign key sebagai primary 
key yang diambil dari kedua entitas yang sebelumnya saling berhubungan.

Unified Modeling Language adalah salah satu standar bahasa yang banyak digunakan di dunia industri untuk medefinisikan requirement, membuat analisis dan desain, serta menggambarkan arstitektur dalam pemograman berorientasi objek.. (Ahluwalia, 2016)

Activity diagram menggambarkan workflow (aliran kerja) atau aktivitas dari sebuah sistem atau proses bisnis atau menu yang ada pada perangkat lunak. (Fridayanthie, 2016)

Use case adalah pemodelan untuk kelakuan (behavior) sistem informasi yang akan dibuat, dan mendeskripsikan sebuah interaksi antara satu atau lebih aktor dengan sistem informasi yang akan dibuat. (Fridayanthie, 2016)

Class diagram merupakan aplikasi yang menggunakan perancangan berorientasi obyek dapat diilustrasikan dalam struktur kelas-kelas dan hubungan antar kelas yang ada. (Prasetyo \& Susanti, 2016)

Class Diagram dibuat setelah diagram use case dibuat terlebih dahulu. Diagram ini harus menjelaskan hubungan apa saja yang terjadi antara suatu objek dengan objek lainnya sehingga terbentuklah suatu sistem aplikasi.(Ayu F \& Permatasari, 2018)

Sequence Diagram Menggambarkan skenario atau interaksi antar objek dalam sebuah sistem berupa pesan yang dikirimkan dan diterima yang digambarkan terhadap waktu .

\section{METODE PENELITIAN}

A. Metode Pengumpulan data

1) Observasi

Penulisan melakukan Pengamatanpengamatan langsung di CV. Kurnia, jln, Balai Pustaka Baru no.46, Jakarta Timur. Karna adanya kegiatan yang berhubungan dengan masakah yang diambil. Hasil dari pengamatan tersebutnlangsung dicatat oleh penulis dan dari kegiatan observasi dapat diketahui kekurangan dalam proses pemasaran penjualan tersebut.

2) Wawancara

Dalam penulisan lapran tugas akhir ini, unruk mendapatkan informasi secara lengkap, maka dari penulis melakukan sesuatu metode tanya jawab langsung ke Bapak Afrizal selaku kepala perusahaan dan beberapa karyawan dan ke konsumen mengenai sistem kegiatan yang sedang berjalan saat ini.

3) Studi Pustaka

Penulisan juga melakukan studi keperpustakaan melalui literature-literature dan referensi e-jurnal maupun buku yang ada di perpustakaan Universitas Bina
Sarana Informatika maupun dari sumber lainnya.

B. Metode Pengembangan Sistem

Pada penelitian ini penulis menggunakan metode System Development Life Cycle yang akan diusulkan, pada metode ini terrdapat tahapan-tahapan anatara lain sebagai berrikut:

1. Analisis

Kebutuhan Perangkat Lunak Proses pengumpulan data dan informasi yang ada CV. Kurnia yang berupa data tertulis atau arsip- arsip yang ada untuk menspesifikasikan kebutuhan perangkat lunak agar dapat difahami perangkat lunak seperti apa yang di butuhkan pengguna. Pada tahap ini perlu untuk di dokumentasikan karena untuk spesifikasi kebutuhan perangkat lunak.

2. Desain

Tahapan ini behubungan dengan kebutuhan sistem yang digunakan untuk mengembangkan aplikasi yang telah dipaparkan pada tahapan kebutuhan sistem. Desain yang digunakan adalah desain antarmuka back-end dan front-end kemudian untuk database menggunakan ERD (Entity Relationship Diagram) dan LRS (Logical Record Structure) serta desain untuk navigasi menggunakan metode hirarki.

3. Coding

Menjelaskan tentang bahasa pemrograman yang digunakan dalam proses pembuatan website ini. Dalam bahasa pemrograman yang digunakan adalah HTML, PHP, CSS, Javascript dan Jquery

4. Testing

Pada tahapan ini website yang telah dibuat akan melalui proses pengujian menggunakan pengujian blackbox testing untuk menguji verifikasi, validasi, dan mendeteksi terjadinya error pada sistem yang telah dibuat. Dari ketiga hal tersebut diharapkan dapat menemukan dan memperbaiki masalah atau kesalahan yang terjadi.

5. Support

Ssebuah website mengalami perubahan ketika sudah dikirimkan ke pengguna, bisa terjadi karena adanya kesalahan yang muncul dan tidak terdeteksi saat pengujian atau perangkat lunak harus beradaptasi dengan lingkungan baru. Tahapan pemeliharaan dapat mengulangi proses pengembangan mulai dari analisis spesifikasi untuk perubahan perangkat lunak baru 


\section{HASIL DAN PEMBAHASAN}

CV. Kurnia merupakan perusahaan yang bergerak dibidang percetakan. Adapun prosedur sistem berjalan di CV. Kurnia masih secara manual sebagai berikut:

1. Proses menerima pesanan

Pelanggan mendatangi toko dan memberikan/memilih contoh undangan yang mau dicetak, setelah memilih pelanggan membawa contoh yang akan dicetak ke designer dan melakukan acc

2. Proses pencetakan.

Designer memberikan hasil desain yg akan dicetak

3. Proses transaksi

Pelanggan membayar total keseluruhan barang yang dipesan.

\section{Activity Diagram Berjalan}

Activity Diagram proses pemesanan barang.

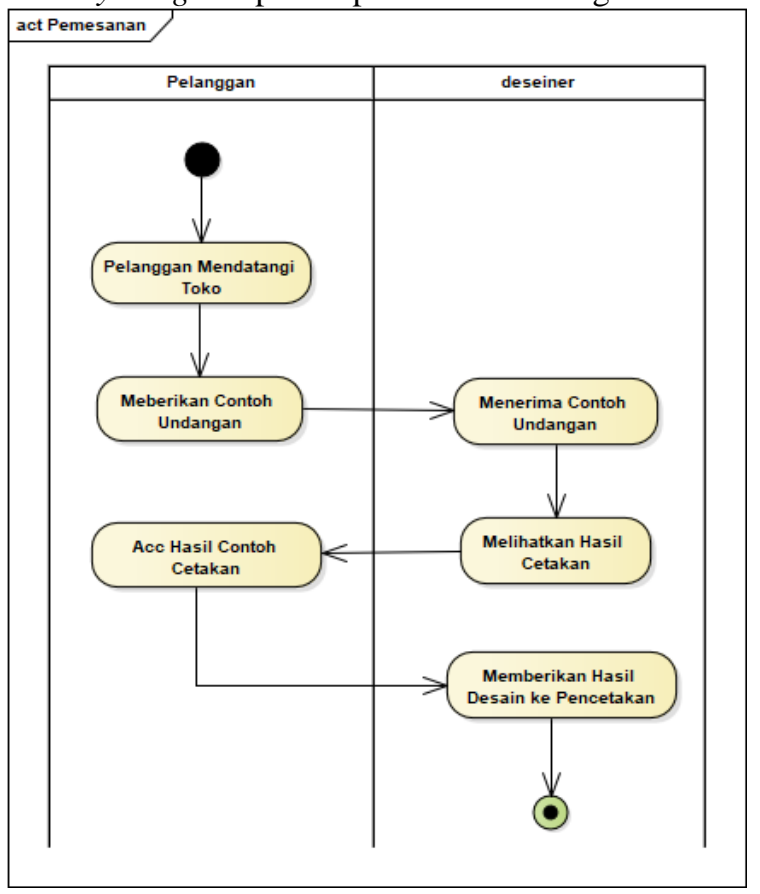

Sumber hasil penelitian:(Andika, Eva Zuraidah)

Gambar 1. Activity Diagram Pemesanan

\section{Analisis Kebutuhan}

Website percetakan kurnia dibangun dengan tujuan pengoptimalkan penyimpanan ijformasi pada percetakan kurnia agar bisa diakses tanpa harus dibatasi ruang dan waktu. Sementara itu pelanggan tidak selalu memiliki waktu untuk mengurus satu bidang saja. Pelanggan pasti ingin mencari kemudahan untuk berinteraksi, yang tetap dapat berhubungan kapanpun dan dimanapun tanpa harus meluangkan waktu untuk datang ke tempat percetakan.

Dari analisa tersebut agar dapat mengoptimalkan penyampaian informasi percetakan
CV Kurnia serta dapat mempermudah pelanggan baik dalam kota maupun luar kota untuk dapat memesan barang sesuai kebutuhan mereka dengan mudah dan cepat.

A. Analisa kebutuhan pelanggan

1) Pelanggan melakukan login untuk melakukan pemesanan

2) Pelanggan malakukan pemesanan

3) Pelanggan melakukan pembayaran yang dipesan

B. Analisa Kebutuhan Admin

1. Admin dapat menambah dan menghapus data produk

2. Proses data transaksi pemesanan

3. Proses laporan data pemesanan

C. Analisa Kebutuhan Sistem

1. Adanya form home untuk pertama kali membuka website

2. Adanya form kategori produk

3. Adanya form jenis produk digunakan untuk melihat detail barang dan pesan

4. Adanya form data pesanan

5. Adanya form cekout melakukan pembayaran

\section{Rancangan Diagram Use Case}

1. Use case user

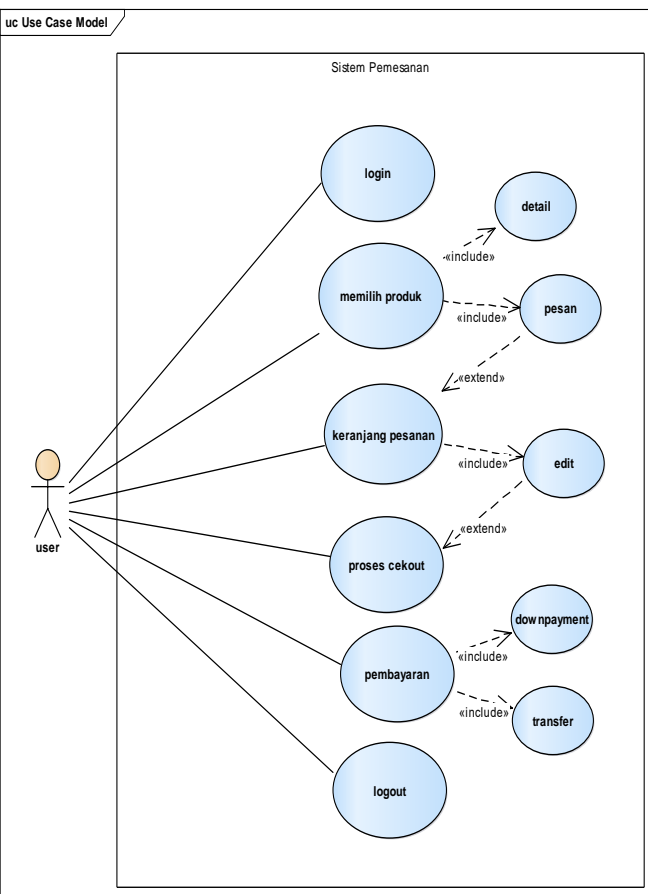

Sumber hasil penelitian:(Andika, Eva Zuraidah) Gambar 2 Use Case User 


\section{Use case Admin}

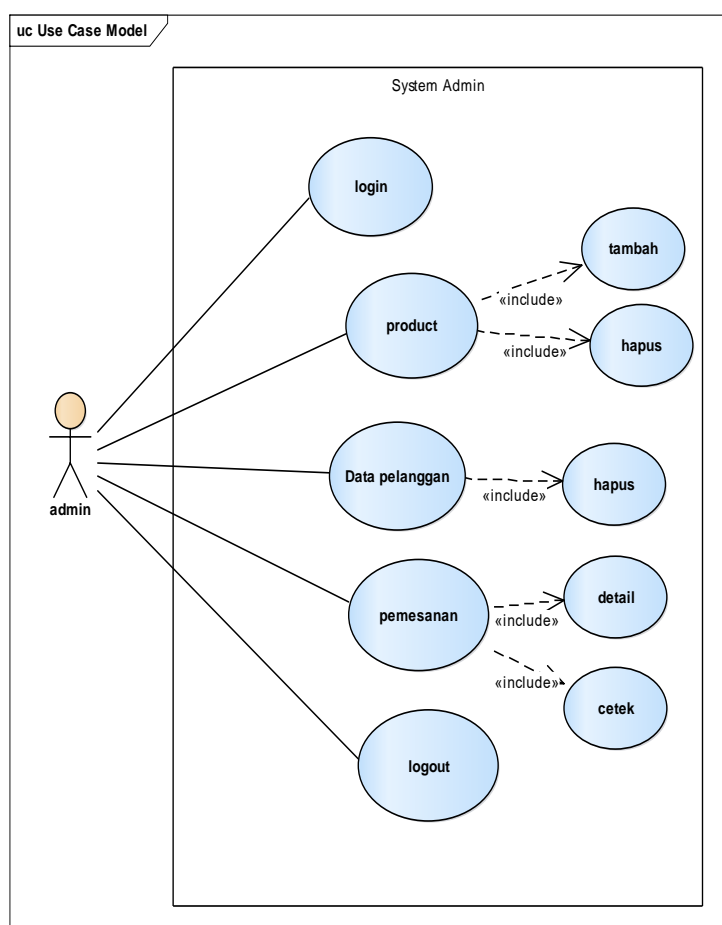

Sumber hasil penelitian:(Andika, Eva Zuraidah)

Gambar 3. Use case Admin 
3. Activity Diagram Pemesanan act Pemesanan

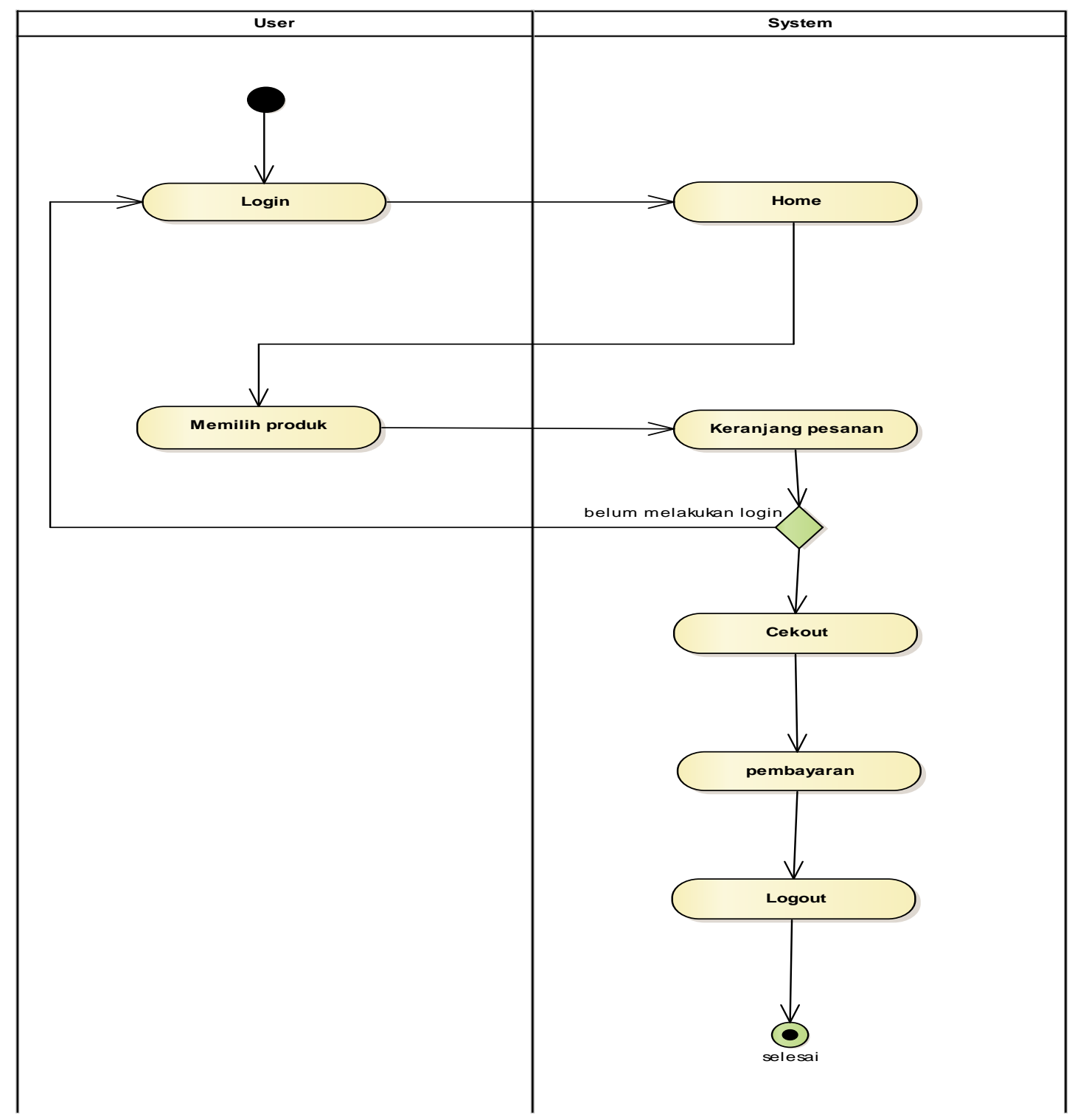

Sumber hasil penelitian:(Andika, Eva Zuraidah)

Gambar 4 Activity Diagram Pemesanan 


\section{Rancangan Perangkat Lunak}

Entity Relationsship Diagram ( ERD)

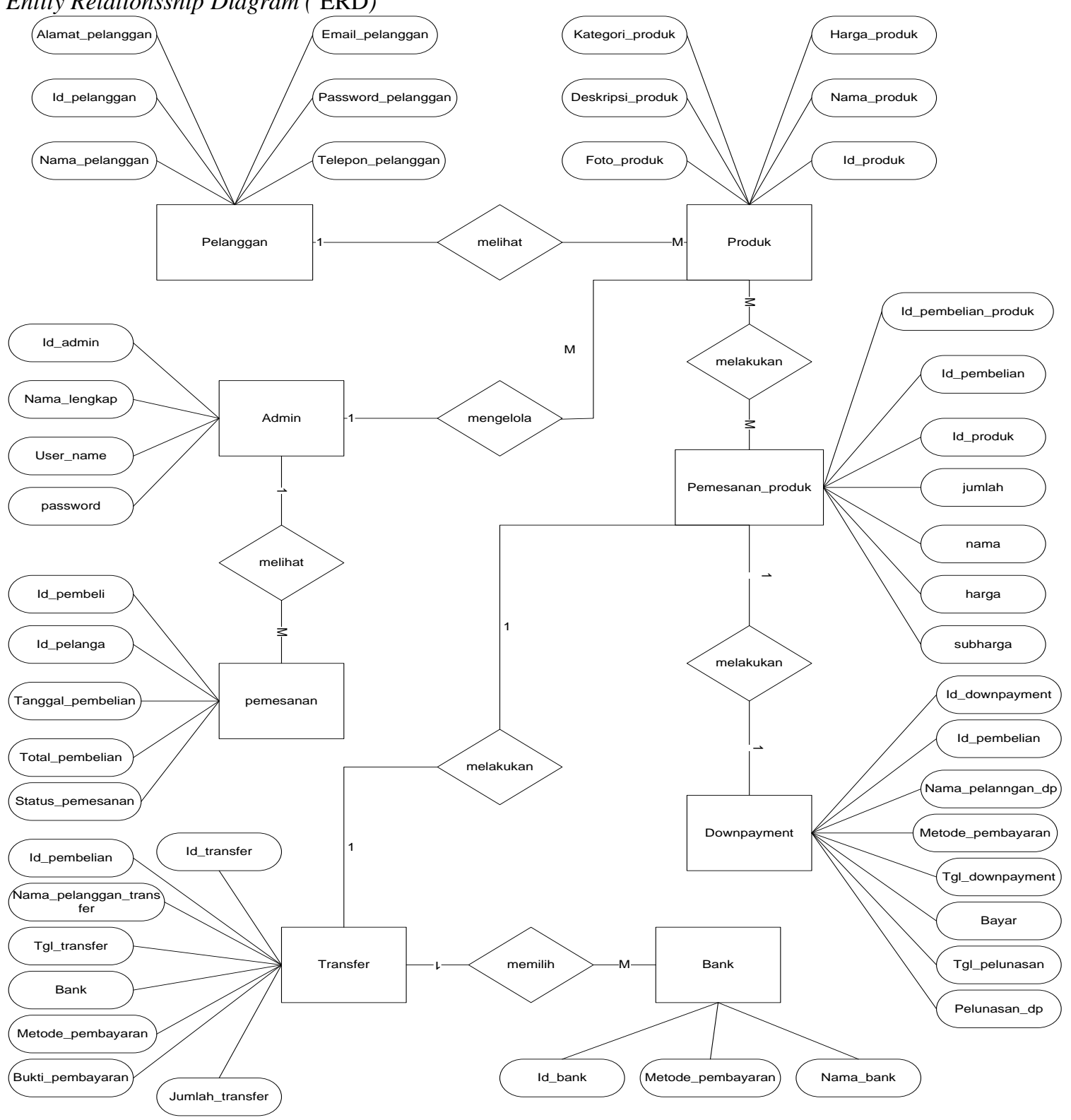

Sumber hasil penelitian:(Andika, Eva Zuraidah)

Gambar 5. Entity Relationsship Diagram ( ERD) 


\section{Logical Record Strukture (LRS)}

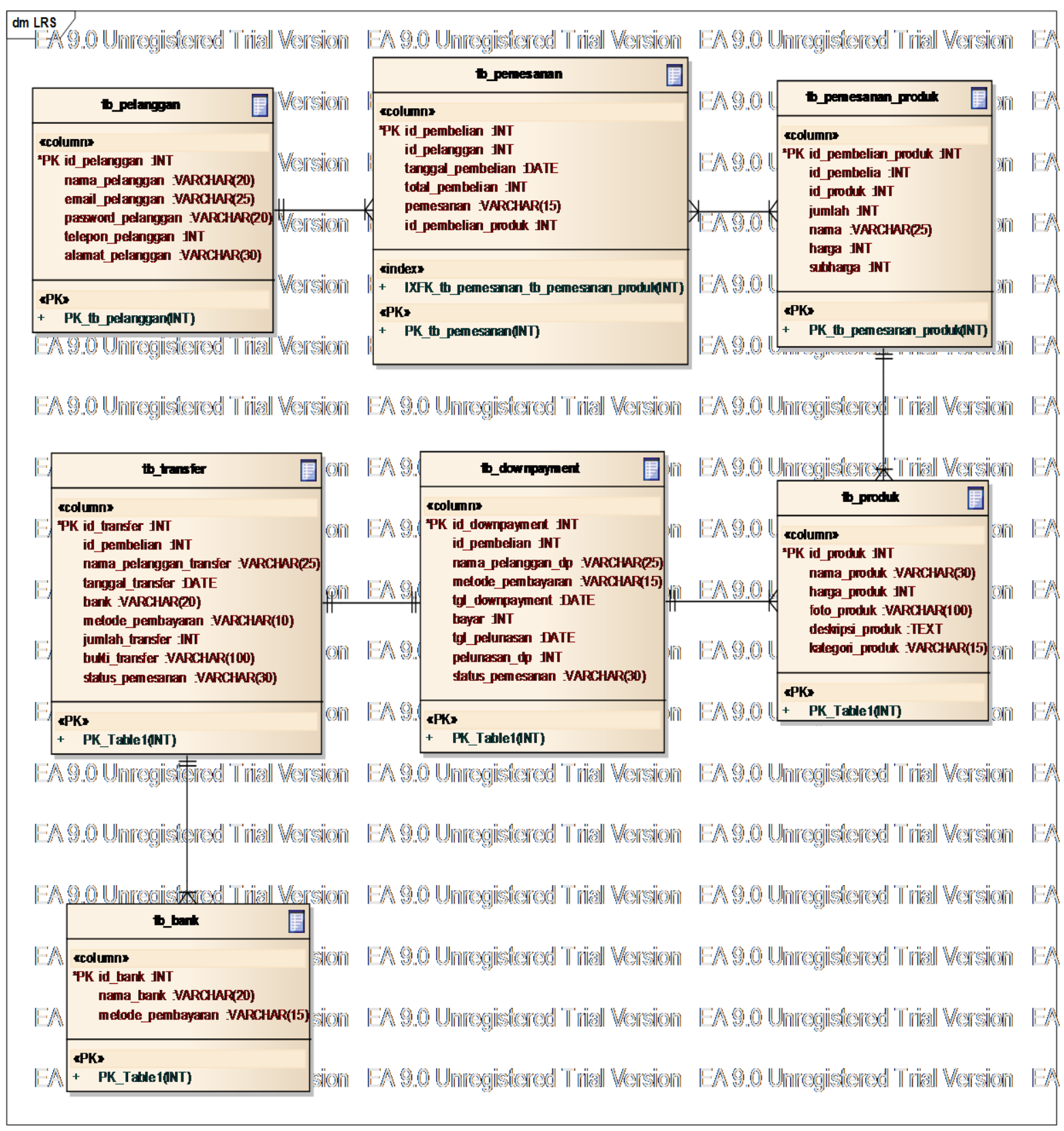

Sumber hasil penelitian:(Andika, Eva Zuraidah)

Gambar 5. Logical Record Strukture (LRS) 


\section{Class Model / Class Diagram}

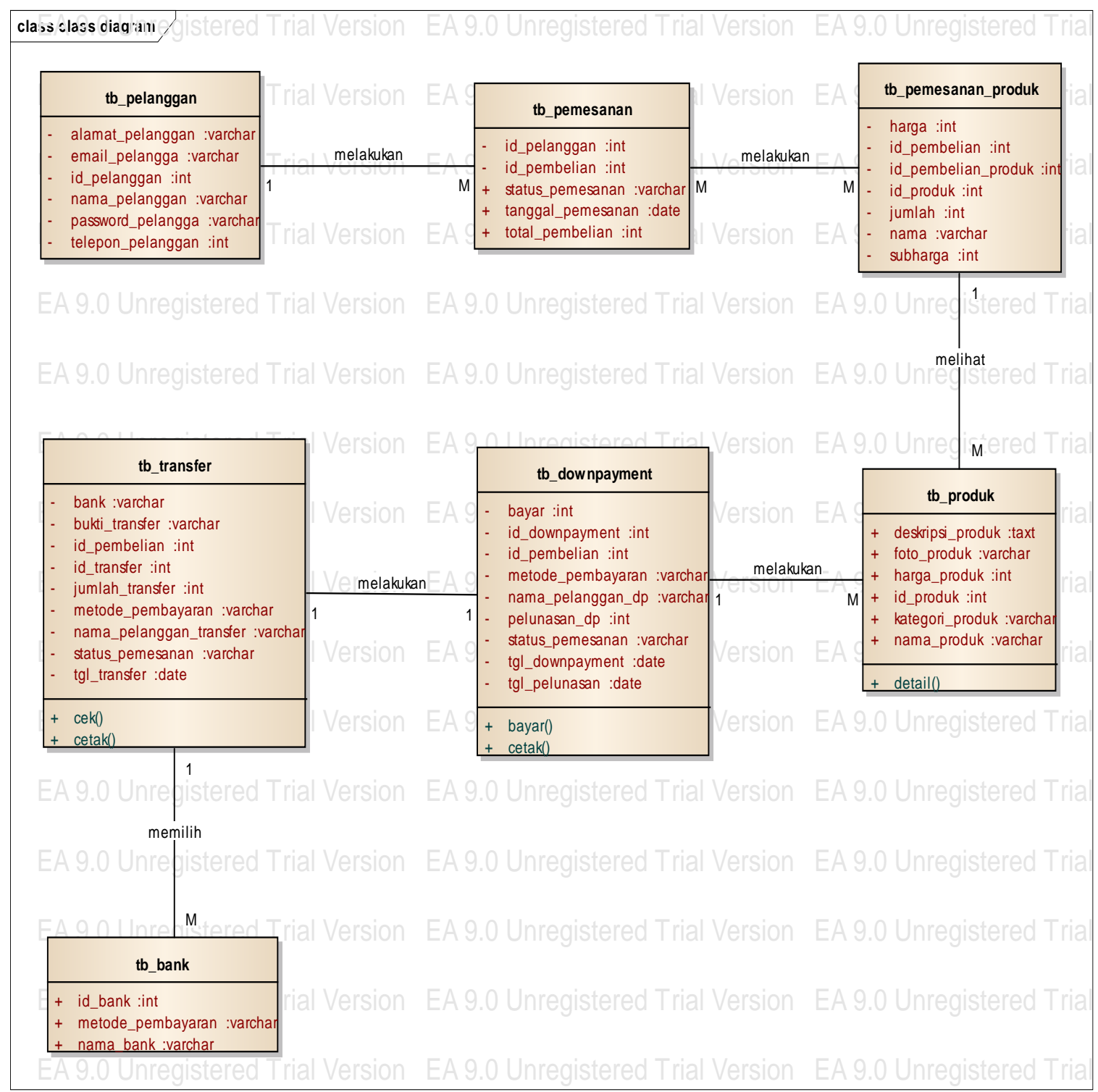

Sumber hasil penelitian:(Andika, Eva Zuraidah)

Gambar 7. Class Model / Class Diagram 


\section{Rancangan Prototype}

A. Interface Tampilan Home

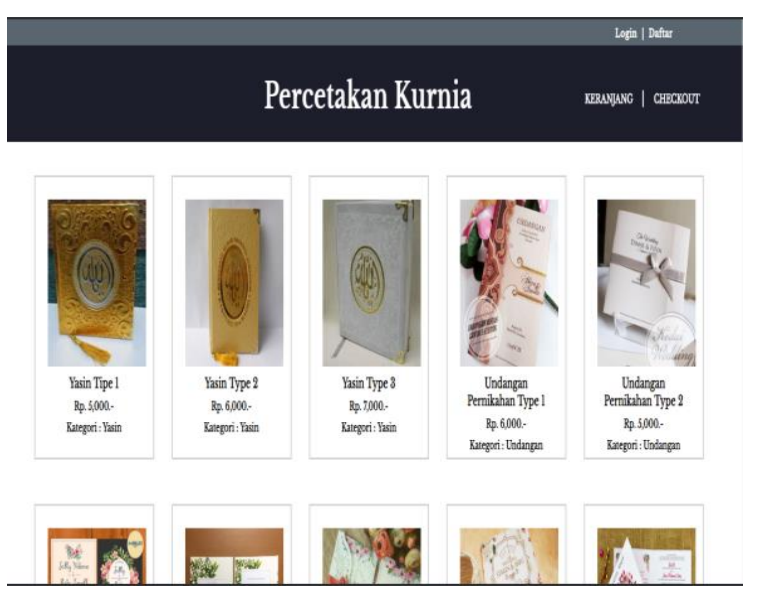

Sumber hasil penelitian:(Andika, Eva Zuraidah Gambar 8. Interface Tampilan Home

Interface Tampilan Login dan Daftar

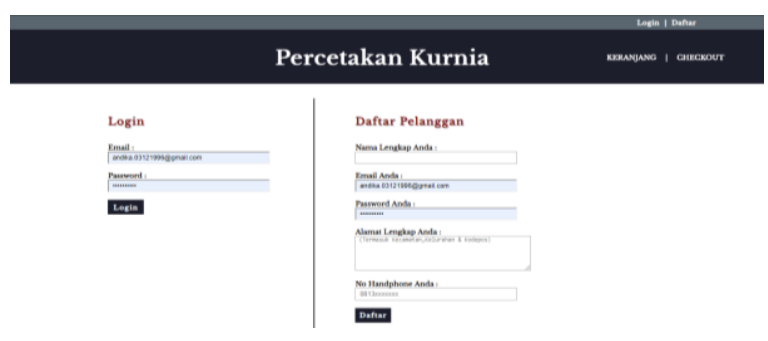

Sumber hasil penelitian: (Andika, Eva Zuraidah)

Gambar 9. Interface Tampilan Login dan Daftar

Interface Tampilan Detail Produk

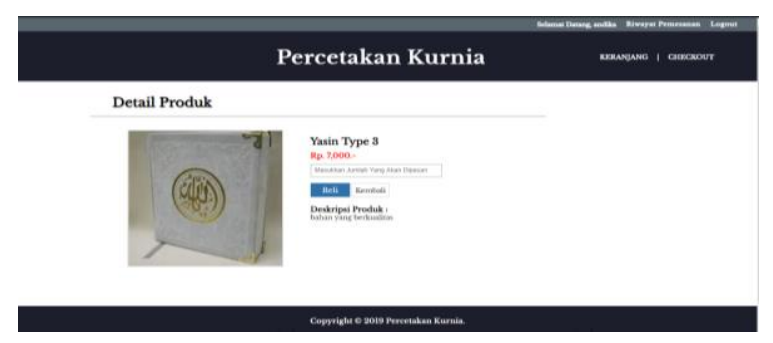

Sumber hasil penelitian:(Andika, Eva Zuraidah)

Gambar 10. Interface Tampilan Detail Produk
Interface Tampilan Keranjang Sumber hasil

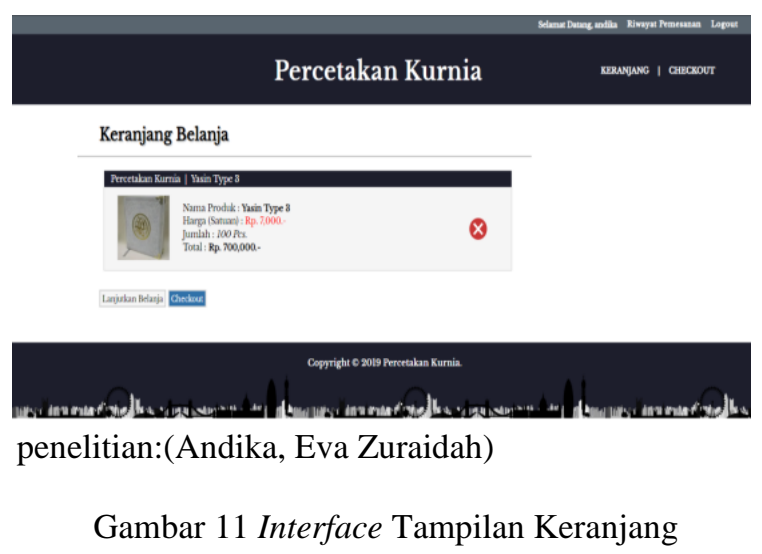

\section{KESIMPULAN}

Berdasarkan tentang pembuatan web yang telah dibahas sebelumnya, maka penulis memberi kesimpulan sebagai berikut:

1. Dengan web ini dapat memberikan kemudahan untuk pelanggan memesan undangan dan yasin tanpa harus datang ketoko.

2. Dengan web ini dapat memberikan informasi produk undangan dan yasin sebelum memesan yang akurat dan update.

3. Dengan adanya web ini pimpinan CV Kurnia dapat melihat laporan pemesanan undangan dan yasin secara cepat dan efisinsi, waktu dan juga efektifitas, sehingga tidak ada lagi kesalahan dalam memasukan data, pemberapa pembayaran yang masuk sesuai dengan pesananan

4. Aplikasi ini sudah dipakai oleh CV Kurnia sampai saat ini.

\section{REFERENSI}

Ahluwalia, M. S (.2016), Approach, I. A. G., Anand, N., Arora, R. U., Articles, S., Basu, K., ... IOSR Journal of Economics and Finance, 3(1), 56. https://doi.org/https://doi.org/10.3929/ethz-b000238666

ANDI. (2015). Kupas Tuntas Pemograman PHP \& MySQL dengan Adobe Dreamweaver CC. ISBN : 978-979-29-5312-1. Penulis : Madcoms. Jakarta.

Ayu, F., \& Permatasari, N. (2018). perancangan sistem informasi pengolahan data PKL pada divisi humas PT pegadaian. Jurnal Infra Tech, 2(2), 12-26. Retrieved from Volume 2, No.2 Oktober 2018 ISSN. 254-0222 http://journal.amikmahaputra.ac.id/index.php/ JIT/article/download/33/25

Gea, S., \& Masalah, P. (2016). Jurnal Sains dan Teknologi Utama, Volume XI, Nomor 3, Desember 2016 163. XI, 163-168. ISSN : 1978-001X0. https://docplayer.info/33276003-Volume-xi- 
nomor-3-desember-2016-issn-x-jurnal-sainsdan-teknologi.html.

Hastanti, R. P., Eka, B., Indah, P., \& Wardati, U. (2015). Sistem Penjualan Berbasis Web (ECommerce ) Pada Tata Distro Kabupaten Pacitan.Vol 3 No 2, 1-9. ISSN: 2338-9761 https://doi.org/10.31294/bi.v3i2.581.

Maryani, I., Ishaq, A., \& Mulyadi, D. S. (2018). Jurnal Evolusi Volume 6 No 2 - 2018. 6(2), 84-90 ISSN: 2338 - 8161 https://ejournal.bsi.ac.id > ejurnal > index.php , evolusi > article > download.

Palopo, A., Palopo, A., Palopo, R. A., \& Kunci, K. (n.d.). Perancangan Sistem Informasi Pemesanan Barang Cetakan Pada Retro Advertising Palopo Berbasis Online Oleh: Ino Sulistiani. Vol 2, No 2 (2014) 95-106

ISSN: $\underline{2541-6499}$ https://doi.org/10.24256/jpmipa.v2i2.116. Prasetyo, A., \& Susanti, R. (2016). Sistem Informasi Penjualan Berbasis Web Pada PT . Cahaya Sejahtera Sentosa Blitar. Vol.10, No.2, Agustus 2016, 1-16 ISSN: 0852-730X https://jurnal.stmikasia.ac.id > index.php > jitika > article > download.

Puspitasari, D., Studi, P., \& Informatika, M. (2016). Sistem Informasi Perpustakaan Sekolah Berbasis Web. Jurnal Pilar Nusa Mandiri, 12(2), 227-240 ISSN: 2549-7421. https://doi.org/10.1016/j.advengsoft.2012.02.0 01

Salamah U, Khasanah. (2017). Sistem Informasi Penjualan Barang Berbasis Web Pada Percetakan Rahayu Bekasi. 6 (1): 61 - 74 (Maret 2018). e-ISSN: 2620-3553. https://repository.atmaluhur.ac.id > bitstream > handle. 